\title{
ASSESSMENT OF GNSS PPP-BASED ZENITH TROPOSPHERIC DELAY
}

\author{
Mohamed ABDELAZEEM ${ }^{1}$, Ahmed EL-RABBANY² \\ ${ }^{1}$ Civil Engineering Department, Aswan University, Egypt \\ ${ }^{2}$ Civil Engineering Department, Ryerson University, Canada \\ e-mails: moh.azm84@gmail.com,rabbany@ryerson.ca
}

\begin{abstract}
This study assesses the precision of zenith tropospheric delay (ZTD) obtained through triple-constellation global navigation satellite system (GNSS) precise point positioning (PPP). Various ZTD estimates are obtained as by-products from GPS-only, GPS/Galileo, GPS/BeiDou, and triple-constellation GPS/Galileo/BeiDou PPP solutions. Triple-constellation GNSS observations from a number of globally distributed reference stations are processed over a period of seven days in order to investigate the daily performance of the ZTD estimates. The estimated ZTDs are then validated by comparing them with the International GNSS Service (IGS) tropospheric products and the University of New Brunswick (UNB3m) model counterparts. It is shown that the ZTD estimates agree with the IGS counterparts with a maximum standard deviation (STD) of $2.4 \mathrm{~cm}$. It is also shown that the precision of estimated ZTD from the GPS/Galileo and GPS/Galileo/BeiDou PPP solutions is improved by about 4.5 and 14\%, respectively, with respect to the GPS-only PPP solution. Moreover, it is found that the estimated ZTD agrees with the UNB3m model with a maximum STD of $3.1 \mathrm{~cm}$. Furthermore, the GPS/Galileo and GPS/Galileo/BeiDou PPP enhance the precision of the ZTD estimates by about 6.5 and 10\%, respectively, in comparison with the GPS-only PPP solution.
\end{abstract}

Keywords: Zenith Tropospheric Delay; triple-constellation GNSS; Precise Point Positioning; IGS tropospheric product; UNB3m tropospheric model

\section{INTRODUCTION}

The troposphere represents the lower part of the Earth's atmosphere, which extends from the Earth's surface up to an altitude of approximately $10 \mathrm{~km}$. Studying the spatiotemporal behavior of the troposphere is important for reliable short-term weather forecasts, climate changes prediction, and global navigation satellite systems (GNSS) signal propagation. The troposphere can be divided into two main components, the hydrostatic and the wet. Both of the hydrostatic and the wet components delay the GNSS signal. The hydrostatic tropospheric delay has little spatial and temporal variations, while the wet tropospheric delay is highly variable. The zenith tropospheric delay (ZTD) is the sum of the zenith hydrostatic delay (ZHD) and the zenith wet delay (ZWD). Therefore, modeling the ZTD has a great importance for precise positioning applications.

Modeling the ZTD using a single GNSS system has been proposed by a number of researchers (e.g., Dousa and Bennitt, 2013; Dousa and Vaclavovic, 2014; Ahmed et al., 2016; Mendez Astudillo et al., 2018; Oikonomou et al., 2018; Ssenyunzi et al., 2019). Moreover, recently, the 
ZTD has been modeled using the multi-constellation GNSS (e.g., Li et al., 2015; Li et al., 2015; Lu et al., 2015; Lu et al., 2017; Ding et al., 2017; Ding et al., 2018; Hu et al., 2018; Li et al., 2018; Pan and Guo, 2018; Zheng et al., 2018; Zhao et al., 2019). Lu et al. (2015) developed a real-time ZTD estimation model using GPS and the BeiDou observations. The observations were processed using the precise point positioning (PPP) technique. The estimated ZTDs from the GPS-only, the BeiDou-only the combined GPS/BeiDou solutions were compared with those obtained from the very-long baseline interferometry (VLBI). Their results showed that the ZTD values obtained from the BeiDou-only solution were less accurate than the GPS-only solution in comparison with the VLBI counterparts. In addition, the accuracy of the ZTD estimates was improved for the combined the combined GPS/BeiDou solution. Pan and Guo (2018) proposed a real-time ZTD estimation model using quad-constellation GNSS observations. The ZTDs were computed through the PPP technique using GNSS observations from various constellations (i.e., GPS-only, GPS/GLONASS, and GPS/GLONASS/Galileo/BDS). The computed ZTDs were compared with the final ZTD products obtained from two different analysis centers. It was shown that the estimated ZTD from the quad-constellation solution has the highest accuracy.

Our study aims to evaluate the precision of the ZTD estimates using triple-constellation GNSS observations, namely GPS, Galileo, and BeiDou. The ZTD estimates presented in this paper are obtained as by-products of four GNSS PPP solutions, namely the GPS-only, GPS/ BeiDou, GPS/Galileo, and GPS/Galileo/BeiDou. GNSS observations from a globally distributed reference stations over a period of seven days are processed using the PPP solution. Then, for validation purposes, the estimated ZTDs are compared with the international GNSS service (IGS) final tropospheric products and the widely used university of New Brunswick (UNB3m) tropospheric model.

\section{ZTD ESTIMATION USING TRIPLE-CONSTELLATION GNSS PPP}

For the PPP solution, dual-frequency ionosphere-free linear combinations of code and carrier phase observations are commonly used. The observation equations can be written as follows (Hofmann-Wellenhof et al., 2008):

$$
\begin{aligned}
& P_{3}=\rho_{r}^{s}+c\left(d t_{r}-d t^{s}\right)+T_{r}^{s}+c\left(D C B_{r, 3}-D C B_{3}^{s}\right)+\varepsilon_{p, 3} \\
& \Phi_{3}=\rho_{r}^{s}+c\left(d t_{r}-d t^{s}\right)+T_{r}^{s}+c\left(\delta_{r, 3}-\delta_{3}^{s}\right)+\overline{\lambda N}+\varepsilon_{\Phi 3}
\end{aligned}
$$

where $P_{3}$ and $\Phi_{3}$ represent the ionosphere-free linear combination of pseudorange and carrier phase observations, respectively; $\rho_{r}^{s}$ is the true geometric distance from satellite to receiver; $c$ is the speed of light; $d t_{r}$ and $d t^{s}$ are the receiver and satellite clock errors, respectively; $T_{r}^{S}$ the tropospheric delay; $D C B_{r, 3}$ and $D C B_{3}^{s}$ are the ionosphere-free differential code bias (DCB) for receiver and satellite, respectively; $\delta_{r, 3}$ and $\delta_{3}^{s}$ are the ionosphere-free differential phase bias for receiver and satellite, respectively; $\overline{\lambda N}$ is the non-integer ambiguity term for phase observations; $\varepsilon_{p, 3}$ and $\varepsilon_{\Phi 3}$ are the code and phase un-modeled residual errors, respectively.

In the un-differenced PPP solution, the receiver DCB is lumped into the receiver clock error. In addition, after using the precise clock products, the PPP model can be reformulated as follows:

$$
\begin{gathered}
\widetilde{P_{3}}=\rho_{r}^{s}+c d t_{r}^{\sim}-c d t_{\text {prec }}^{s}+T_{r}^{s}+\varepsilon_{p, 3} \\
\widetilde{\Phi_{3}}=\rho_{r}^{s}+c d t_{r}^{\sim}-c d t_{p r e c}^{s}+T_{r}^{s}+\widetilde{N}+\varepsilon_{\varepsilon_{\Phi 3}}
\end{gathered}
$$


where $\widetilde{P_{3}}$ and $\widetilde{\Phi_{3}}$ are the ionosphere-free linear combination of pseudorange and carrier phase observations, respectively, after applying the precise products; $d t_{r}^{\sim}$ is the sum of the receiver clock error and the receiver DCB $d t_{r}^{\tilde{r}}=d t_{r}+D C B_{r, 3} ; d t_{p r e c}^{s}$ is the precise satellite clock product; $\widetilde{N}$ is the ambiguity parameter, as given below:

$$
\widetilde{N}=\left(\frac{f_{1}^{2} \lambda_{1} N_{1}-f_{2}^{2} \lambda_{2} N_{2}}{f_{1}^{2}-f_{2}^{2}}+D_{r}-D^{s}\right)
$$

where $\lambda_{1}$ and $\lambda_{2}$ are wavelengths of the $\mathrm{L}_{1}$ and $\mathrm{L}_{2}$ carrier frequencies, respectively; $N_{1}$ and $N_{2}$ are the non-integer ambiguity parameters on $\mathrm{L}_{1}$ and $\mathrm{L}_{2}$, respectively, including the initial fractional phase bias for the receiver and satellite; $D_{r}$ is the difference between receiver differential code and phase biases; $D^{s}$ is the difference between satellite differential code and phase biases.

The tropospheric delay $\left(T_{r}^{S}\right)$ can be divided into a hydrostatic part and a wet part. The tropospheric delay's mathematical formula can be expressed as follows:

$$
T_{r}^{s}=Z_{h} \times M F_{h}+Z_{w} \times M F_{w}
$$

where $Z_{h}$ and $Z_{w}$ refer to the ZHD and the ZWD, respectively; $M F_{h}$ and $M F_{w}$ are the hydrostatic and the wet mapping functions, respectively. The hydrostatic and wet global mapping functions (GMFs) (Böhm et al., 2006) are used in this study. The ZHD can be computed using the Saastamoinen model (Saastamoinen, 1972), with meteorological data obtained from the global pressure and temperature 2 (GPT2) model (Lagler et al., 2013), while the ZWD is estimated as unknown parameter in the PPP solution.

For the triple-constellation GNSS PPP solution, the unknown parameters vector $(\boldsymbol{X})$ take the following formula (Afifi and El-Rabbany, 2016):

$$
\boldsymbol{X}=\left(\begin{array}{c}
\Delta x \\
\Delta y \\
\Delta z \\
c d t_{r} \\
Z_{w} \\
I S B \\
\widetilde{N}
\end{array}\right)
$$

where $\Delta x, \Delta y$, and $\Delta z$ are the corrections to the receiver coordinates; ISB represents the intersystem bias, which is the difference in receiver DCB between two satellite systems.

\section{TRIPLE-CONSTELLATION GNSS DATA SETS}

In our study, six globally distributed IGS multi-GNSS experiment (IGS-MGEX) reference stations have been used (Figure 1). The reference stations have been selected from different latitudes and heights in order to represent different tropospheric characteristics (Table1). Tripleconstellation GNSS observations for seven consecutive days (day of year (DOY) 1 to 7 in 2018) were downloaded (BKG, 2020). The examined days have been selected in order to assess the daily performance of the proposed ZTD estimation model. 


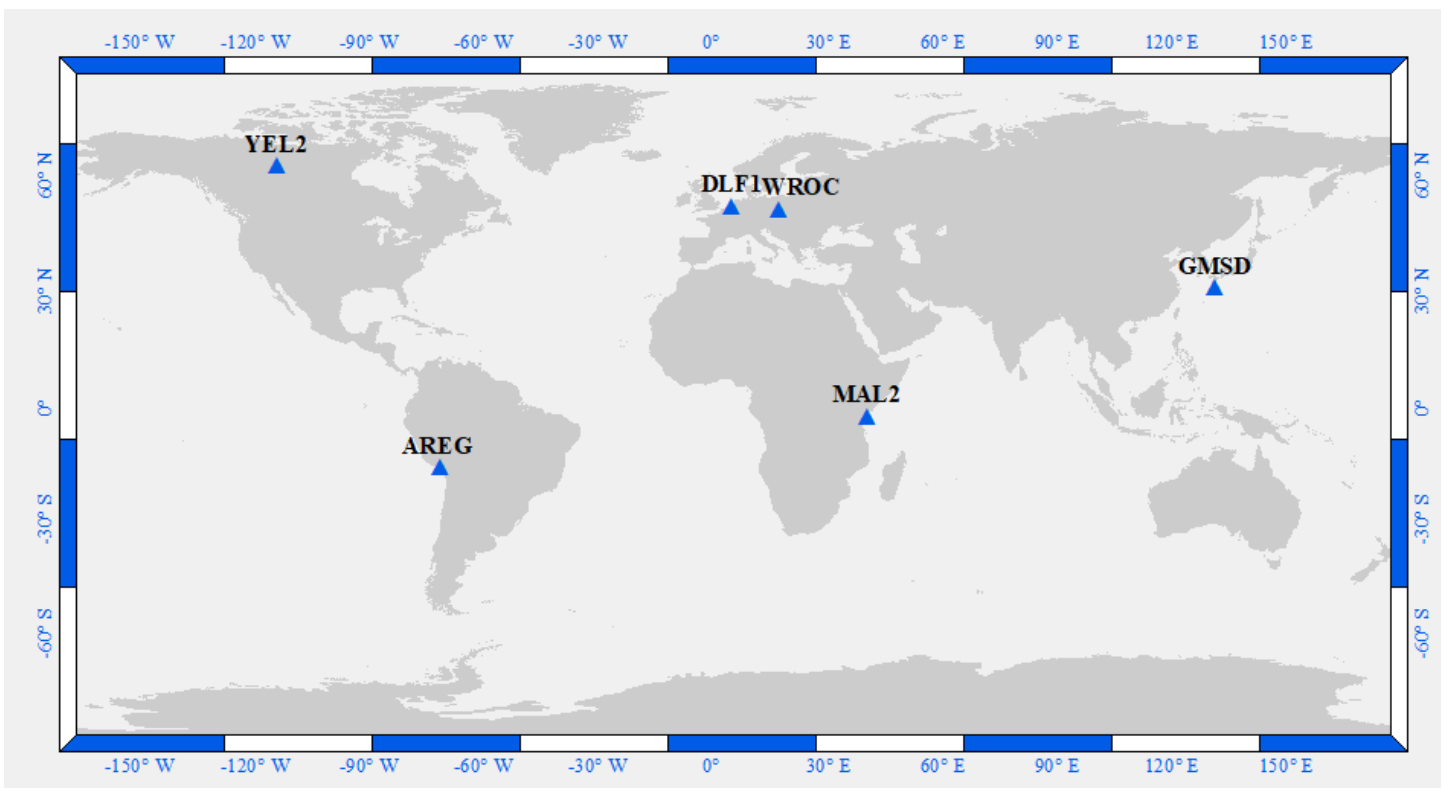

Figure 1. Geographic location of the examined stations

Table 1. Geographical properties of the examined stations

\begin{tabular}{|c|c|c|c|}
\hline Station & Longitude & Latitude & Height (m) \\
\hline YEL2 & $-114.4808^{\circ}$ & $62.4813^{\circ}$ & 181.008 \\
\hline DLF1 & $4.3875^{\circ}$ & $51.9860^{\circ}$ & 75.800 \\
\hline WROC & $17.0620^{\circ}$ & $51.1132^{\circ}$ & 180.300 \\
\hline GMSD & $131.0155^{\circ}$ & $30.5564^{\circ}$ & 142.648 \\
\hline MAL2 & $40.1941^{\circ}$ & $-2.9961^{\circ}$ & -20.900 \\
\hline AREG & $-71.4929^{\circ}$ & $-16.4654^{\circ}$ & 2489.337 \\
\hline
\end{tabular}

Each observation file has a 30-second time interval with 24-hour time span. The elevation angle has been selected to equal $10^{\circ}$. In order to estimate the ZTD, the triple-constellation GNSS measurements have been processed using the PPP technique using the PPPH software (Bahadur and Nohutcu, 2018).

PPPH is a MATLAB-based analysis software, which is capable of processing GPS, GLONASS, Galileo, and BeiDou observations. PPPH is a graphical user interface (GUI) software that consisting of five steps (Figure 2). Each step is presented with a separate tab, which summarizes the step function (Figure 2). For the data importing step, the data should be imported with the standard exchange formats, including RINEX, SP3, CLK, DCB, and ATX. The preprocessing step involves the selection of elevation mask angle, cycle slip detection, clock jump detection, code smoothing and processing mode (i.e., static or kinematic). The modeling step includes the correction of satellite orbit and clock errors and the elimination of first-order ionospheric error using the ionosphere-free linear combination. In addition, the ZHD is determined using the Saastamoinen model with the meteorological data acquired from the GPT2 model. The GMF is used for both of the hydrostatic and wet tropospheric components. The IGS absolute antenna model is used in order to correct for the antenna phase center offset (PCO) and the antenna phase center variation (PCV). Moreover, the relativistic effect, phase wind-up, and site displacement effects, including solid Earth tides and ocean loading, are corrected using the appropriate models. For the parameter estimation step, the extended Kalman filter is used. 
Statistical parameters, including positioning errors and convergence time, and a number of plotting options (e.g., 3D positioning error and ZTD) are provided as part of the solution.

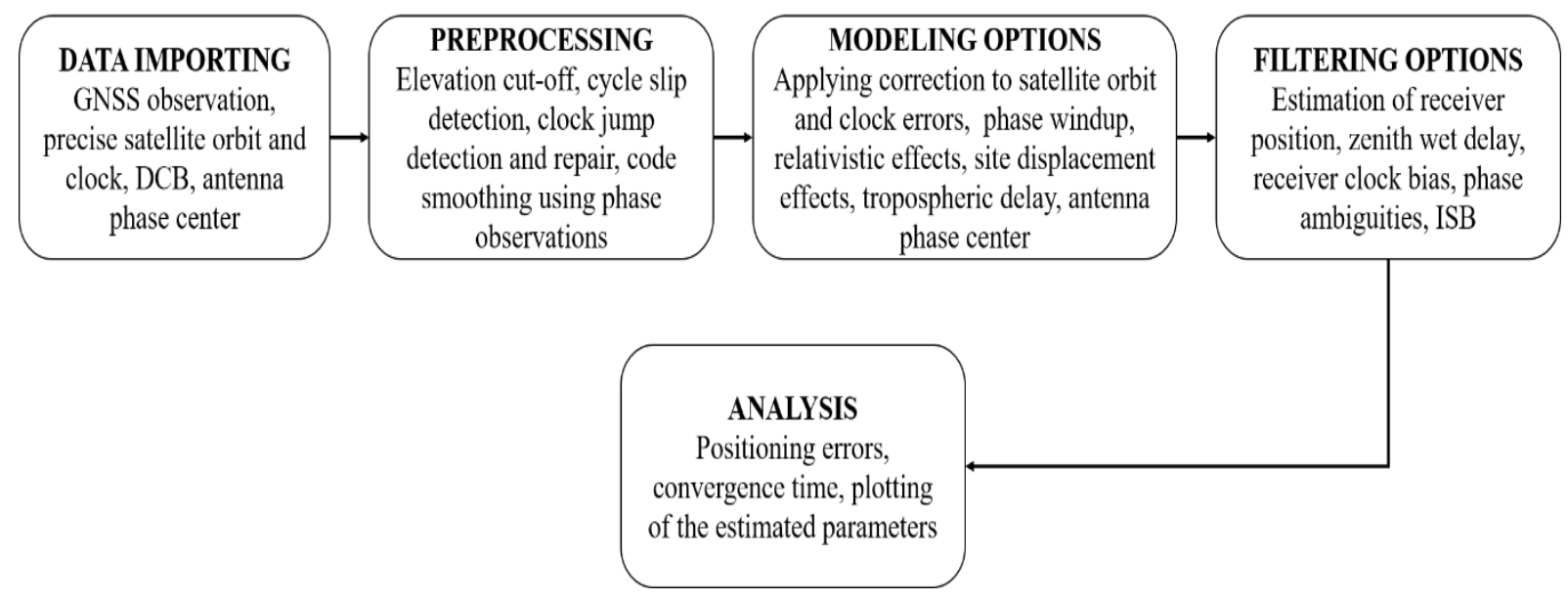

Figure 2. Flowchart of PPPH processing steps

For the processing of our data, the precise IGS-MGEX satellite orbit and clock products have been used (IGS-MGEX, 2020). In addition, the publicly available IGS Earth orientation parameters have been used (IGS, 2020). The ZTD is determined every 15-minute time interval.

\section{RESULTS AND ANALYSIS}

To obtain the ZTD, the triple-constellation GNSS (i.e., GPS, Galileo, and BeiDou) observations collected at the examined stations are processed using the PPPH software. The ZTD is estimated by combining different GNSS observations into four PPP scenarios, which are the GPSonly (G), GPS/BeiDou (G+B), GPS/Galileo (G+E), and GPS/BeiDou/Galileo (G+B+E) solutions. Subsequently, the ZTD are estimated as by-products of the four PPP solutions. The convergence time of the obtained ZTD from the four PPP solutions over the examined stations are calculated. The ZTD is converged, when the difference between the ZTD estimates (i.e., GPS/BeiDou, GPS/Galileo, and GPS/BeiDou/Galileo PPP solutions) and the GPS-PPP derived ZTD is less than $2 \mathrm{~cm}$. Similar convergence times are obtained for each station over the examined days. Therefore, for illustration purpose only, the convergence times of the ZTD estimates over the examined stations on DOY 1, 2018 as examples are given in Figure 3. It can be seen that the ZTD is converged after 7, 4, 14, 9, 8, and 5 minutes for stations YEL2, DLF1, WROC, GMSD, MAL2, and AREG, respectively. 

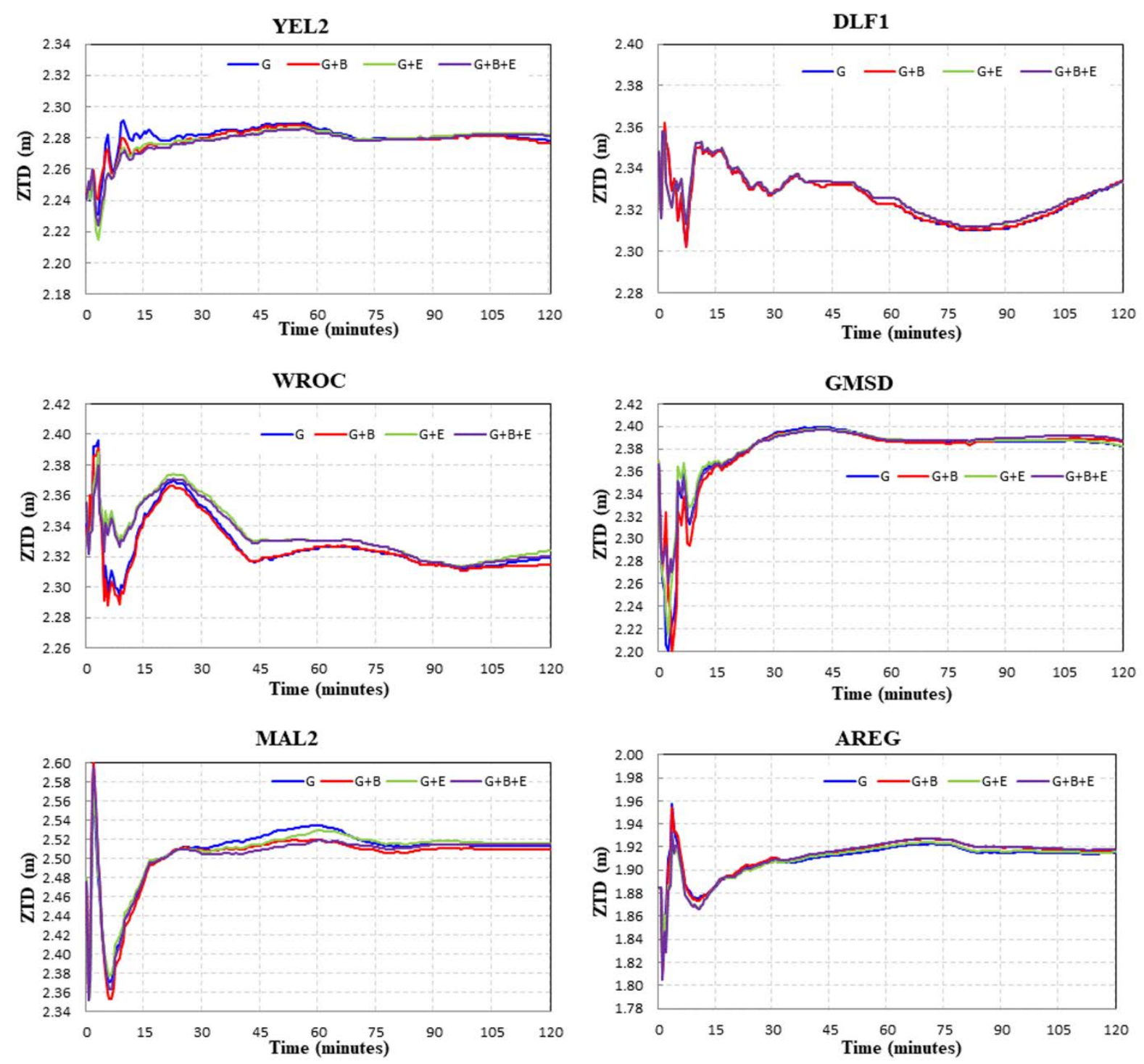

Figure 3. Convergence time of the ZTD estimates for the examined stations DOY 1, 2018

Figure 4 illustrates the ZTD time series over seven days at the examined stations. As can be seen, station-pertinent ZTD estimates obtained from the various GNSS PPP models exhibit similar behavior, and their values are largely similar. The estimated GPS/BeiDou ZTDs, however, are slightly noisier than the other models. This is likely attributed to the low precision of the PCO and PCV models for the BeiDou system, which might degrade the ZTD estimation (Xu et al., 2013 and Lu et al., 2015). It is also noticed that the ZTD values at station AREG are smaller than those at other stations. This is likely due to the much higher altitude of station AREG (i.e., 2,489.337 m). On the other hand, the ZTD values at station MAL2 are slightly higher than the other stations. This is attributed to its low altitude (i.e., $-20.900 \mathrm{~m}$ ), which means that the GNSS signal travels more distance through the troposphere. Moreover, the ZTD at station GMSD is slightly high on DOY 4 and 7 . This is potentially attributed to the high value of the water vapor and humidity on these two examined days. 

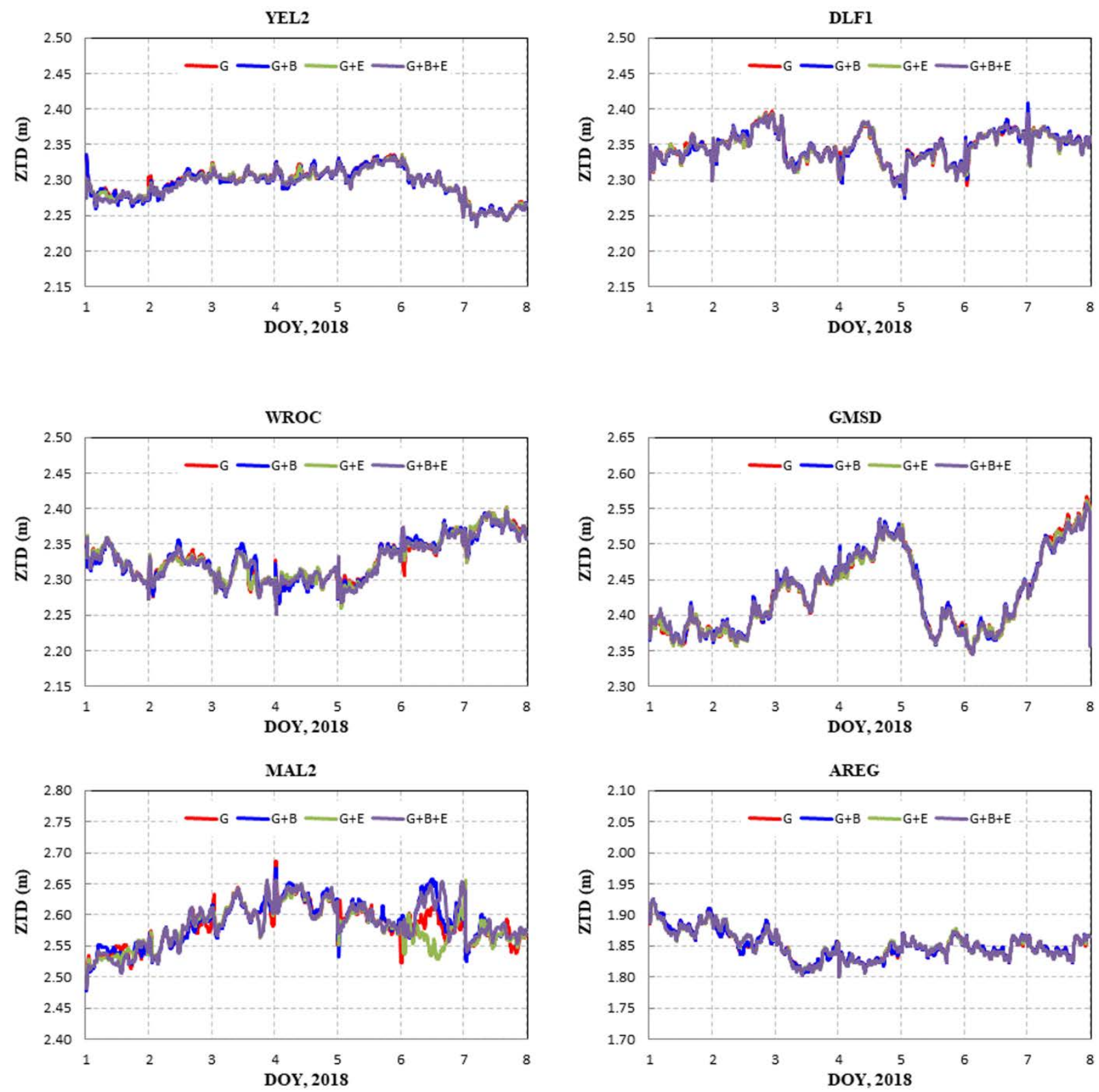

Figure 4. ZTDs time series over the examined stations

The linear correlation between the ZTD estimates over the examined stations for the days under consideration is calculated and is given in Figure 5. It is clear that the estimated ZTD from the GPS/BeiDou, GPS/Galileo, and GPS/BeiDou/Galileo PPP solutions are highly correlated with the estimated ZTD from the GPS-only PPP solutions. The correlation coefficients between the GPS-only ZTD estimates and GPS/BeiDou ZTD estimates is 0.999, while its values are 0.9987 and 0.9983 for the GPS/Galileo and GPS/BeiDou/Galileo ZTD estimates, respectively. 

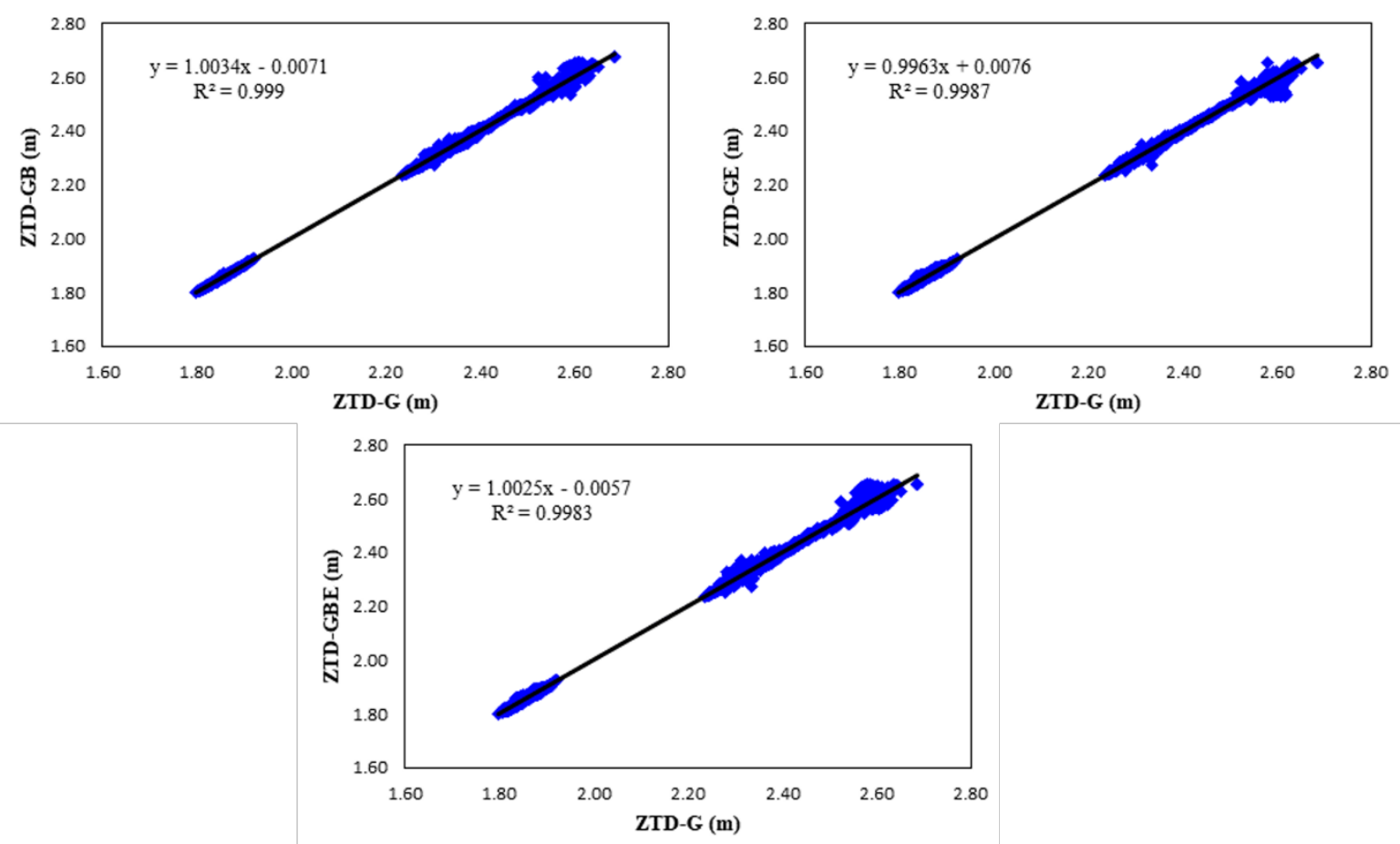

Figure 5. Correlation of ZTD estimates over the examined stations

To investigate the daily variability of the ZTD estimates, the standard deviation (STD) for the ZTD estimates over the examined stations for the days under considerations are determined and presented in Figure 6. It is shown that the STDs of the ZTD estimates over the examined stations are less than $5 \mathrm{~cm}$. An exception is station GMSD, which has a ZTD STD ranging from $4.5 \mathrm{~cm}$ to $7 \mathrm{~cm}$. This is essentially due to the fact that the ZTD values are high on DOY 4 and 7, as mentioned earlier. Also, it is noticed that the STDs at the start of the time series are relatively high for the all stations. This is attributed to the convergence time of the PPP solution, and consequently the ZTD. It is also observed that there are some model-dependent differences in the estimated STDs at station WROC for the period from 12- to 16-hour universal time (UT). This can be attributed to the fact that the tropospheric parameters (i.e., temperature and water vapor) are high over the station during this period. Moreover, the STD of the ZTD estimates are different at station MAL2. This is due to the fact that station MAL2 is located within the equatorial region, where the tropospheric parameters are highly variable. 

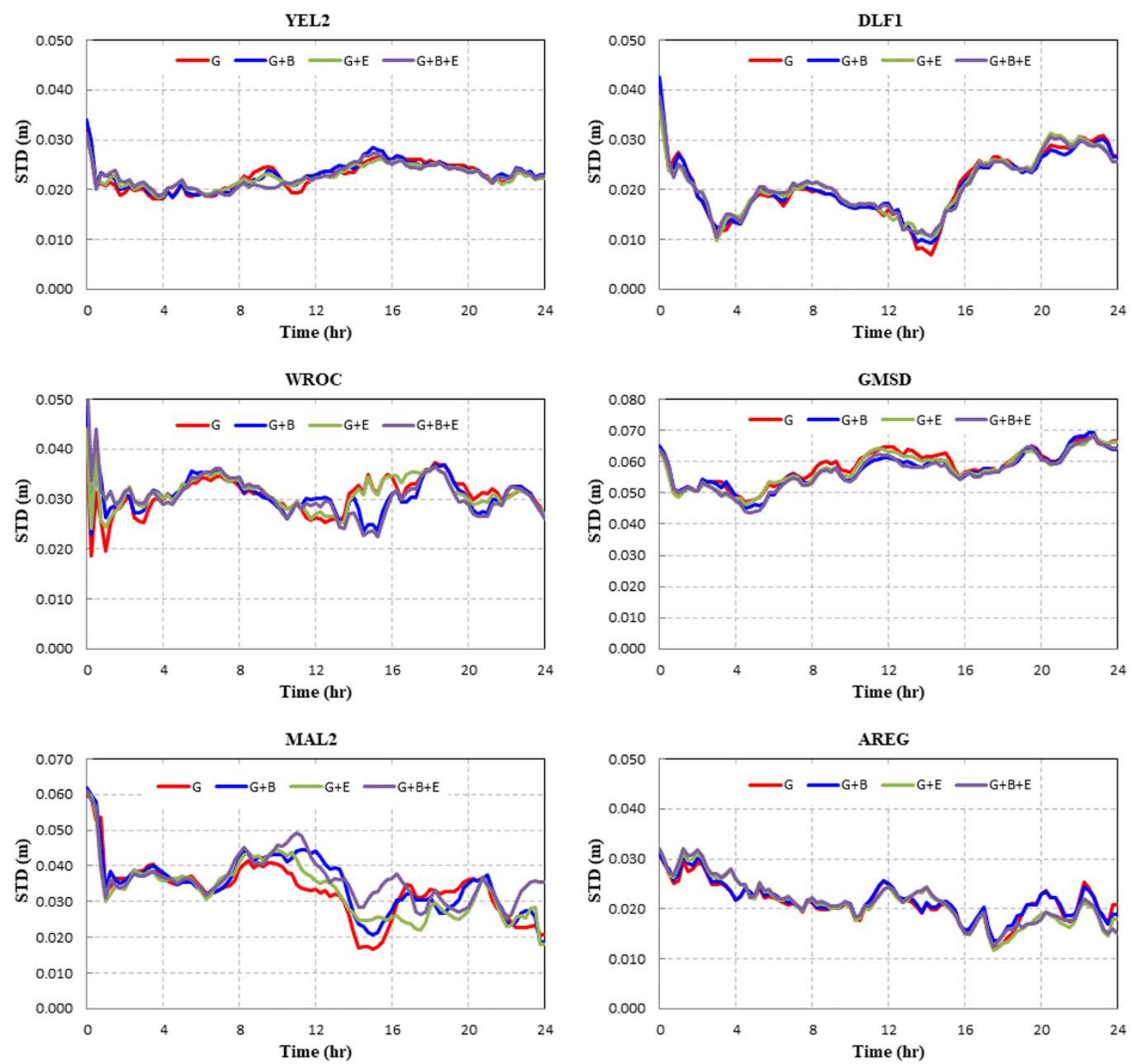

Figure 6. ZTD standard deviation values for the seven examined days

\subsection{Validation with the IGS final tropospheric products}

In order to validate the triple-constellation GNSS ZTD estimation, the computed ZTDs are compared with the final IGS tropospheric products (IGS, 2020) at the selected stations. The ZTDs are determined every 15 minutes (i.e., 96 values per day for each station) and then compared with those of the IGS counterparts. The STDs of the differences are determined and summarized in Figure 7. 

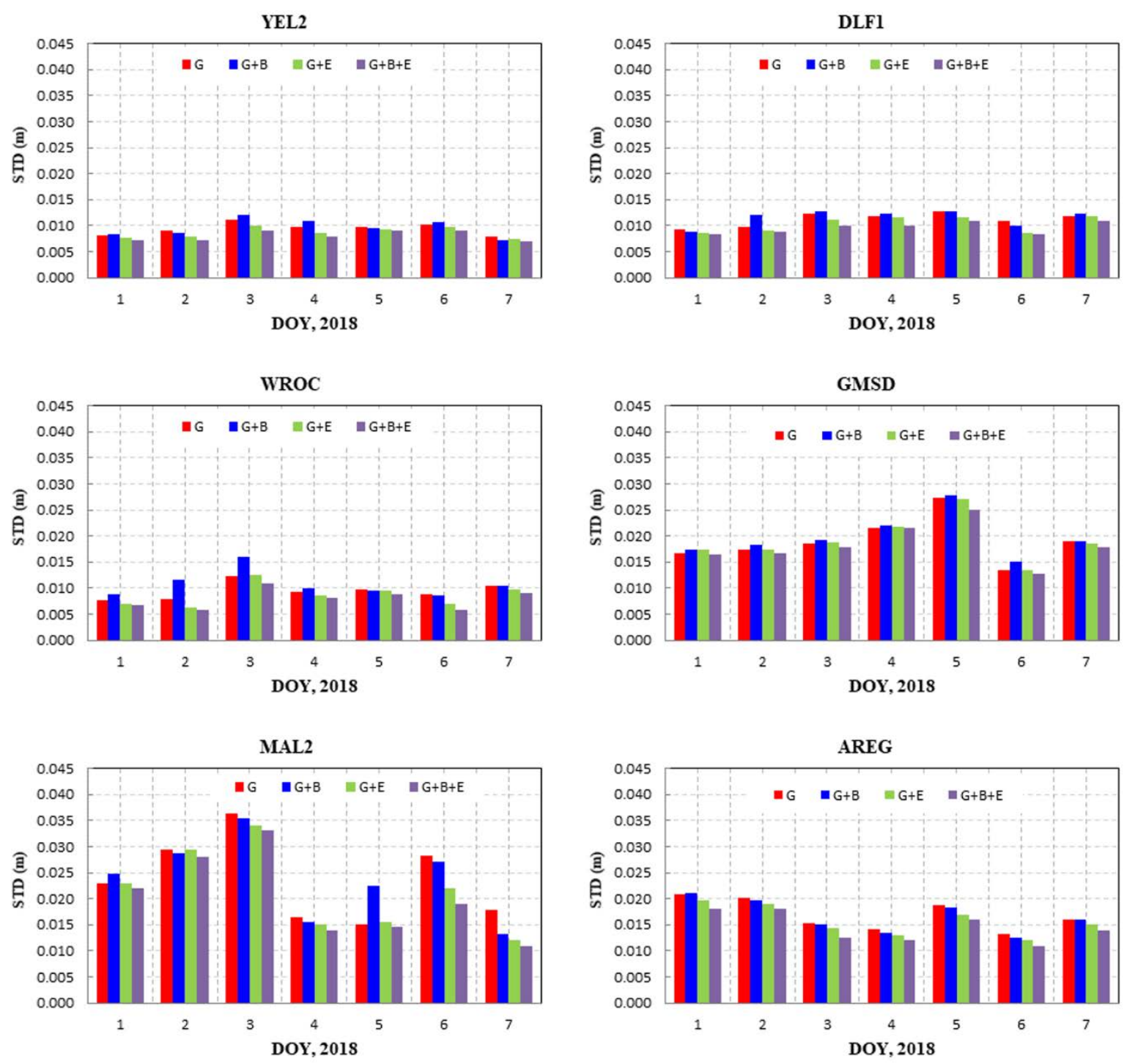

Figure 7. STDs for the differences between the ZTD estimates and the IGS counterparts

It is shown that the precision of the ZTD estimates is improved when the GPS/BeiDou/Galileo PPP solution is used. In addition, the precision of the ZTD obtained through the GPS/Galileo PPP solution is better than those obtained through the GPS-only and GPS/BeiDou PPP solutions. This is due to the larger number of tracked GPS/Galileo satellites, which improves the satellite geometry. In addition, the Galileo PPP solution is more stable, particularly after applying the new antennas calibrations (i.e., IGS14.atx), which enhances the precision of the ZTD estimates (Baldysz et al., 2017). It also can be seen that the STD values of the GPS/BeiDou ZTD estimates are larger than those of the GPS-only ZTD estimates. This is attributed to the relatively lower accuracy of the BeiDou satellite orbits and clock products in comparison with those of GPS (Feng et al., 2019).

It is also clear that the STDs at station MAL2 are larger than those at other stations. This essentially is due to the fact that station MAL2 is located within the equatorial region, where the weather conditions (i.e., temperature, water vapor, and humidity) are highly variable. In addition, the STD of ZTD estimates at stations GMSD and AREG are slightly larger than the other stations. This is attributed to the fact that station GMSD is a high-humidity coastal station. For station AREG, however, this is due to its high altitude. 
In order to further evaluate the precision of the ZTD estimates, the distribution of their differences with respect to the IGS counterparts are presented in Figure 8. In addition, the mean and the STD values for the differences are estimated and given also in Figure 8. It is shown that the STD of the ZTD differences are 0.022, 0.024, 0.021 and $0.019 \mathrm{~m}$ for the GPS-only, GPS/BeiDou, GPS/Galileo, and GPS/BeiDou/Galileo PPP solutions, respectively. Therefore, it can be said that the GPS/Galileo and GPS/BeiDou/Galileo PPP solutions enhance the precision of the estimated ZTD by about 4.5 and 14\%, respectively, with respect to the GPS-only PPP solution.
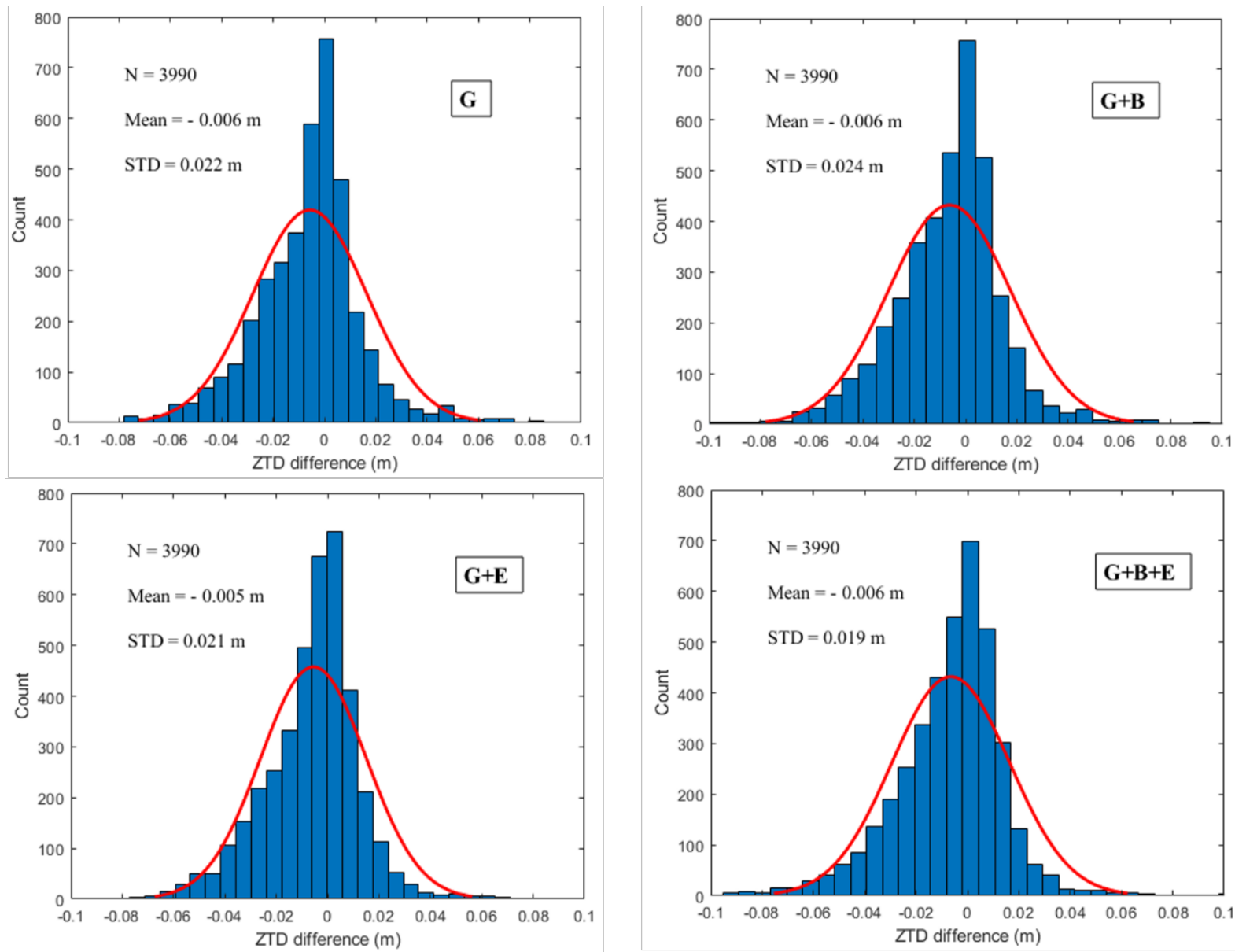

Figure 8. Distribution of the differences between the ZTD estimates and the IGS counterparts

\subsection{Validation with the UNB3m tropospheric model}

To further verify the precision of the ZTD estimation, the ZTD obtained through the four PPP solutions are compared with those obtained through the widely used UNB3m tropospheric model (Leandro et al., 2008). The STD values for the differences are estimated and given in Figure 9. Figure 9 shows the STD values of the differences between the ZTD estimates, and the UNB3m counterparts over the examined stations. It is shown that the ZTD estimates have good agreement with the UNB3m model, where the STD values are less than $5 \mathrm{~cm}$. In addition, it can be seen that the STD values for stations GMSD and MAL2 are slightly higher than the other stations. This is attributed to the stations location, which are located at a coast and equatorial region for stations GMSD and MAL2, respectively. 


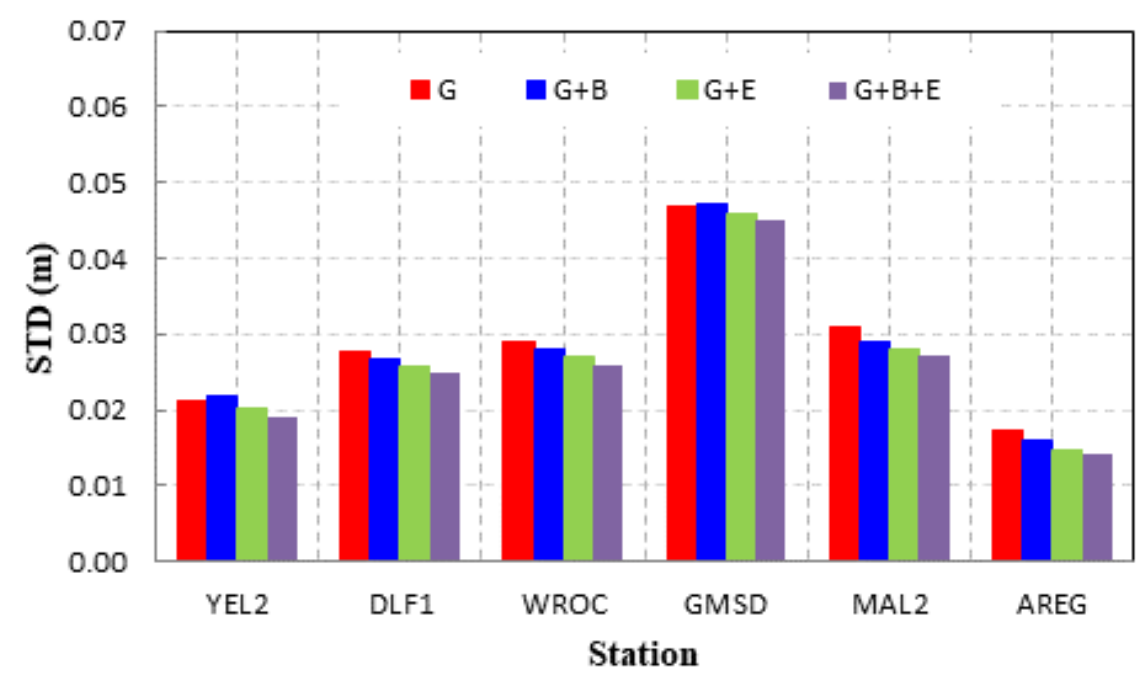

Figure 9. STDs for the differences between the ZTD estimates and the UNB3m model

To further validate the ZTD estimates with respect to the UNB3m model, the statistical analysis for the differences between the ZTD values and the model counterparts is computed. Table 2 summarizes the statistical parameters for the ZTD differences. As can be seen in Table 2, the precision of the obtained ZTD through the GPS/BeiDou, GPS/Galileo, and GPS/BeiDou/Galileo PPP solutions is improved by about 3.2, 6.5 and 10\%, respectively, in comparison with those obtained through the GPS-only PPP solution.

Table 2. Statistics of the difference between the ZTD estimates and the UNB3m model

\begin{tabular}{|c|c|c|c|c|}
\hline Parameter (m) & GPS & GPS/BeiDou & GPS/Galileo & GPS/BeiDou/Galileo \\
\hline Max & 0.057 & 0.056 & 0.054 & 0.052 \\
\hline Min & -0.091 & -0.093 & -0.088 & -0.089 \\
\hline Mean & -0.013 & -0.014 & -0.013 & -0.014 \\
\hline STD & 0.031 & 0.030 & 0.029 & 0.028 \\
\hline
\end{tabular}

\section{CONCLUSION}

The objective of this paper is to assess the precision of the estimated ZTD using tripleconstellation GNSS observations. Triple-constellation GNSS observations from a number of globally distributed reference stations spanning a period of seven days have been used. PPP solutions have been obtained using single-, dual-, and triple-constellation GNSS observations. The estimated ZTDs have been obtained as by-products through the GPS-only, the GPS/BeiDou, the GPS/Galileo, and the GPS/BeiDou/Galileo PPP solutions. The estimated ZTDs have been compared with the IGS final tropospheric products counterparts as well as the UNB3m model. It has been shown that the ZTD estimates are comparable with those of the IGS and UNB3m model counterparts, with maximum STDs of 2.4 and $3.1 \mathrm{~cm}$, respectively. Using the IGS tropospheric product as a reference, it has been shown that the GPS/Galileo and GPS/Galileo/BeiDou PPP solutions have enhanced the precision of the ZTD estimates by about 4.5 and 14\%, respectively, in comparison with the GPS-only PPP solution. These ratios are increased to 6.5 and $10 \%$, respectively, when the UNB3m is taken as a reference. This shows that multi-constellation PPP-based ZTD has the potential to be used in nowcasting and weather monitoring applications. 


\section{REFERENCES}

Afifi, A., El-Rabbany, A., Jin, S. (2016) Un-differenced precise point positioning model using triple GNSS constellations. Cogent Geoscience, 2: 1223899.

Ahmed, F., Václavovic, P., Teferle, F. N., Douša, J., Bingley, R., Laurichesse, D. (2016) Comparative analysis of real-time precise point positioning zenith total delay estimates. GPS Solutions, 20, 187-199.

Bahadur, B., Nohutcu, M. (2018) PPPH: a MATLAB-based software for multi-GNSS precise point positioning analysis. GPS Solutions, 22:113

Bałdysz, Z., M. Szołucha, M., Nykiel, G., M. Figurski, M. (2017) Analysis of the Impact of Galileo Observations on the Tropospheric Delays Estimation. Baltic Geodetic Congress (BGC Geomatics), Gdansk, 2017, pp. 65-71.

BKG, Agency for Cartography and Geodesy, (2020) Available from https://igs.bkg.bund.de/ dataandproducts/rinexsearch. Accessed on July $1^{\text {st }}, 2020$.

Boehm, J., Niell, A., Tregoning, P., Schuh, H. (2006) Global Mapping Function (GMF): A new empirical mapping function based on numerical weather model data. Geophysical Research Letters, 33, 1-4

Ding, N., Zhang, S., Wu, S., Wang, X., Kealy, A., Zhang, K. (2018) A new approach for GNSS tomography from a few GNSS stations. Atmospheric Measurement Techniques, 11, 3511-3522.

Ding, W., Teferle, F. N., Kazmierski, K., Laurichesse, D., Yuan, Y. (2017) An evaluation of real-time troposphere estimation based on GNSS Precise Point Positioning. Journal of Geophysical Research: Atmospheres, 122, 2779-2790.

Dousa, J., Bennitt, G. V. (2013) Estimation and evaluation of hourly updated global GPS Zenith Total Delays over ten months. GPS Solutions, 17, 453-464.

Dousa, J., Vaclavovic, P. (2014) Real-time zenith tropospheric delays in support of numerical weather prediction applications. Advances in Space Research, 53, 1347-1358.

Feng, P., Li, F., Yan, J., Barriot, J. P. (2019) Evaluation of the zenithal total delay estimates from BeiDou/GPS combined signals in the frame of the IGS MGEX project. Acta Geodaetica et Geophysica, 54, 71-87.

Hofmann-Wellenhof, B., Lichtenegger, H., Walse, E. (2008) GNSS Global Navigation Satellite Systems: GPS, GLONASS, Galileo, and More. Springer, New York

Hu, P., Huang, G., Zhang, Q., Wang, X., Mao, M. (2018) Algorithm and Performance of Precipitable Water Vapor Retrieval Using Multiple GNSS Precise Point Positioning Technology. China Satellite Navigation Conference (CSNC) 2018 Proceedings. CSNC 2018. Lecture Notes in Electrical Engineering, 497, 139-151.

IGS, International GNSS Service, (2020) Available from ftp://cddis.gsfc.nasa.gov/. Accessed on July $1^{\text {st }}, 2020$.

IGS-MGEX, IGS Multi-GNSS Experiment, (2020) Available from ftp://cddis.gsfc.nasa.gov/ gps/ products /mgex. Accessed on July $1^{\text {st }}, 2020$.

Lagler, K., Schindelegger, M., Bohm, J., Krasna, H., Nilsson, T. (2013) GPT2: Empirical slant delay model for radio space geodetic techniques. Geophys Res Lett, 40, 1069-1073.

Leandro, R. F., Langley, R. B., Santos, M. C. (2008) UNB3m_pack: a neutral atmosphere delay package for radiometric space techniques. GPS Solutions, 12, 65-70. 
Li, X., Dick, G., Lu, C., Ge, M., Nilsson, T., Ning, T., Wickert, J., Schuh, H. (2015) MultiGNSS Meteorology: Real-Time Retrieving of Atmospheric Water Vapor from BeiDou, Galileo, GLONASS, and GPS Observations. IEEE Transactions on Geoscience and Remote Sensing, 53, 6385-6393.

Li, X., Tan, H., Li, X., Dick, G., Wickert, J., Schuh, H. (2018) Real-Time Sensing of Precipitable Water Vapor from BeiDou Observations: Hong Kong and CMONOC Networks. Journal of Geophysical Research: Atmospheres, 123, 7897-7909.

Li, X., Zus, F., Lu, C., Dick, G., Ning, T., Ge, M., Wickert, J., Schuh, H. (2015) Retrieving of atmospheric parameters from multi-GNSS in real time: Validation with water vapor radiometer and numerical weather model. Journal of Geophysical Research: Atmospheres, 120, 71897204.

Lu, C., Chen, X., Liu, G., Dick, G., Wickert, J., Jiang, X., Zheng, K., Schuh, H. (2017) RealTime Tropospheric Delays Retrieved from Multi-GNSS Observations and IGS Real-Time Product Streams. Remote Sensing, 9, 1317.

Lu, C., Li, X., Nilsson, T., Ning, T., Heinkelmann, R., Ge, M., Glaser, S., Schuh, H. (2015) Real-time retrieval of precipitable water vapor from GPS and BeiDou observations. Journal of Geodesy, 89, 843-856.

Mendez Astudillo, J., Lau, L., Tang, Y. T., Moore, T. (2018) Analysing the Zenith Tropospheric Delay Estimates in On-line Precise Point Positioning (PPP) Services and PPP Software Packages. Sensors (Basel), 18.

Oikonomou, C., Tymvios, F., Pikridas, C., Bitharis, S., Balidakis, K., Michaelides, S., Haralambous, H., Charalambous, D. (2018) Tropospheric delay performance for GNSS integrated water vapor estimation by using GPT2w model, ECMWF's IFS operational model and in situ meteorological data. Advances in Geosciences, 45, 363-375.

Pan, L., Guo, F. (2018) Real-time tropospheric delay retrieval with GPS, GLONASS, Galileo and BDS data. Sci Rep, 8, 17067.

Saastamoinen, J. (1972). Contributions to the theory of atmospheric refraction. Bulletin Géodésique, 105, 279-298

Ssenyunzi, R. C., Oruru, B., Mutonyi D’ujanga, F., Realini, E., Barindelli, S., Tagliaferro, G., Van De Giesen, N. (2019) Variability and accuracy of Zenith Total Delay over the East African tropical region. Advances in Space Research, 64, 900-920.

Xu, A., Xu, Z., Ge, M., Xu, X., Zhu, H., Sui, X. (2013) Estimating zenith tropospheric delays from BeiDou navigation satellite system observations. Sensors (Basel), 13, 4514-4526.

Zhao, Q., Yao, Y., Cao, X., Yao, W. (2019) Accuracy and reliability of tropospheric wet refractivity tomography with GPS, BDS, and GLONASS observations. Advances in Space Research, 63, 2836-2847.

Zheng, F., Lou, Y., Gu, S., Gong, X., Shi, C. (2018) Modeling tropospheric wet delays with national GNSS reference network in China for BeiDou precise point positioning. Journal of Geodesy, 92, 545-560.

Received: 2020-07-16

Reviewed: 2020-07-25 (undisclosed name), 2020-08-31 (undisclosed name)

Accepted: 2020-12-08 